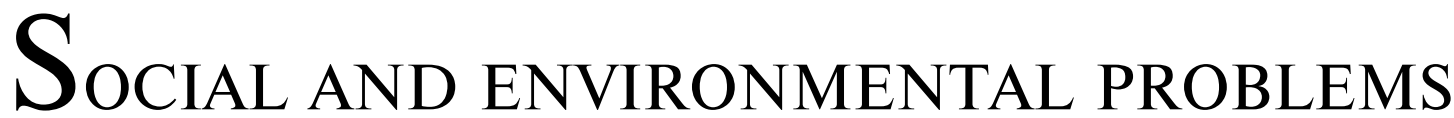 OF SUSTAINABLE DEVELOPMENT
}

УДК 37.013.73

\section{ИАЕИ УСТОЙЧИВОГО РАЗВИТИЯ В СОАЕРЖАНИИ ЕСТЕСТВЕННОНАУЧНЫХ АИСЦИПАИН}

\author{
Е. Н. ДЗЯТКОВСКАЯ ${ }^{1)}$ \\ ${ }^{1)}$ Институт стратегии развития образования Российской академии наук \\ ул. Жуковского, 16, 105062, г. Москва, Россия
}

\begin{abstract}
Рассматривается роль естественнонаучного образования в контексте современного экологического кризиса и путей выхода из него. Актуализируются особенности образования для устойчивого развития, его вызовы к обновлению содержания естественнонаучных дисциплин. Обосновываются такие векторы, как отражение современного состояния науки, фундаментальность знаний, их междисциплинарная интеграция, мировоззренческая направленность. Сделан вывод о том, что для понимания междисциплинарной концепции устойчивого развития недостаточно совокупности специальных научных картин мира. Поставлена проблема разработки естественнонаучной картины мира как экологической составляющей образования в интересах устойчивого развития. Определяются базовые категории систематизации естественнонаучных знаний: природа, материальное единство мира, развитие, система, самоорганизация, детерминизм и др. Утверждается, что естественнонаучная картина мира в ее экологическом аспекте опирается на учение В. И. Вернадского о биосфере и биогеохимической миграции атомов, учение Н. Н. Моисеева об универсальном эволюционизме и концепцию устойчивого развития. Сделано заключение о роли естественнонаучного образования в формировании ключевого понятия устойчивого развития - экологического императива.
\end{abstract}

Ключевые слова: естественнонаучная картина мира; материальное единство мира; развитие; система; самоорганизация; детерминизм.

Образец цитирования:

Дзятковская ЕН. Идеи устойчивого развития в содержании естественнонаучных дисциплин. Журнал Белорусского государственного университета. Экология. 2021;2:4-14. https://doi.org//10.46646/2521-683X/2021-2-4-14
For citation:

Dzyatkovskaya EN. Ideas of sustainable development in the content of science disciplines. Journal of the Belarusian State University. Ecology. 2021;2:4-14. Russian. https://doi.org//10.46646/2521-683X/2021-2-4-14

\section{Aвтор :}

Елена Николаевна Дзятковская - доктор биологических наук, профессор; ведущий научный сотрудник лаборатории дидактики и философии образования.
Author:

Elena N. Dzyatkovskaya, doctor of science (biology), professor; senior researcher at the laboratory of didactics and philosophy of education.

dziatkov@mail.ru 


\title{
IDEAS OF SUSTAINABLE DEVELOPMENT IN THE CONTENT OF SCIENCE DISCIPLINES
}

\author{
E. N. DZYATKOVSKAYA

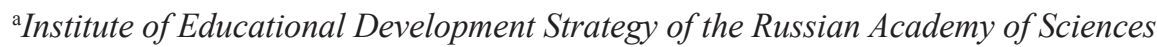 \\ 16 Zhukovsky Street, Moscow 105062, Russia
}

\begin{abstract}
The article deals with the role of science education in explaining the modern environmental crisis and ways out of it. The urgency and peculiarities of education for sustainable development, its challenges to updating the content of natural science disciplines are considered. The directions of such updating are justified: reflection of modern state of science, fundamentality of knowledge, its interdisciplinary integration and worldview orientation. The conclusion is made that for understanding the interdisciplinary concept of sustainable development the set of special scientific pictures of the world is not enough. The problem of developing a natural-science picture of the world as an environmental component of education for sustainable development is posed. The article considers the basic categories of synthesis of natural-science knowledge into the natural-science picture of the world: nature, material unity of the world, development, system, self-organization, determinism, etc. It is determined that the natural scientific picture of the world, in its ecological aspect, is based on V. I. Vernadsky's doctrine on the biosphere and biogeochemical migration of atoms, N. N. Moiseev's doctrine on universal evolutionism, and the concept of sustainable development. It is concluded about the role of the natural sciences in the formation of the key concept of sustainable development - the ecological imperative.
\end{abstract}

Keywords: natural scientific picture of the world; material unity of the world; development, system; self-organization; determinism.

\section{Введение}

Мировое сообщество приняло 17 целей устойчивого развития (ЦУР), которых необходимо достичь совместными действиями всех стран до 2030 г., чтобы затормозить скорость нарастания глобальных проблем [1]. Если это не получится, с 30-х гг. XXI в. может начаться совсем другой, трагический сценарий развития цивилизации. По словам Генерального секретаря ООН Антониу Гутерриш, человечество уже сегодня столкнулось с четырьмя всадниками апокалипсиса - раздор (геополитическая напряженность и глобальное недоверие), голод как результат нарастающих климатических изменений, завоеватель - злоупотребление новыми технологиями, риски использования искусственного разума, смерть - болезни цивилизации, пандемия коронавируса [2]. Неотложный характер решения глобальных проблем требует осуществления фундаментальных преобразований во всех сферах жизни общества, которые обеспечили бы движение человечества по пути устойчивого развития. Необходимым условием такого движения, способным изменить ситуацию, в которой оказалось человечество, является образование в интересах устойчивого развития (ОУР) [3]. Образование, направленное на достижение целей устойчивого развития, должно учить решать проблемы, справляться с возникающими сложностями и потенциальными рисками, формировать устойчивость к неблагоприятному воздействию и способность системно и творчески мыслить. В связи с этим ЮНЕСКО призывает обеспечить закрепление за ОУР роли основополагающего компонента системы образования на всех ее уровнях; интегрировать принципы ОУР в общеобразовательные программы и программы профессиональной подготовки всех уровней. Важнейшим направлением обновления общего и профессионального образования является естественнонаучная область, способная объяснять закономерности изменений в биосфере, анализировать лимитирующие факторы сохранения ее экологического равновесия, изучать проблемы, связанные с исчерпанием природных ресурсов, изменением климата и др. Пути обновления содержания естественнонаучного образования обсуждаются в следующих направлениях:

Во-первых, обращается внимание на включение в содержание образования научных знаний, соответствующих современному уровню развития науки и необходимых для решения жизненно важных задач устойчивого развития, формирования естественнонаучной функциональной грамотности, соответствующей вызовам XXI в. По единодушному мнению членов Римского клуба, молодежь во всем мире продолжает «учиться по учебникам с идеями из 1950-х гг, основанных на теориях 1850-х гг» [4].

Во-вторых, речь идет о необходимости усиления мировоззренческой направленности естественнонаучного образования, о формировании образа мира через призму культуры: систему социокультурных ценностей, культурных универсалий, отражающих отношение человека к природе, к обществу, другим людям и самому себе, ценностно-смысловую оценку тех или иных его событий и явлений. Мировоззренческая направленность естественнонаучного образования неразрывно связывается с формируемой культурой устойчивого развития и гуманистическим характером решения глобальных проблемы на основе ценности сохранения на планете всех культур и народов [1]. 
B-третьих, усиление фундаментальности знаний, направленности естественнонаучного образования на формирование научной картины мира, как компонента современного мировоззрения. Научная картина мира - особый тип научного теоретического знания. Это специфическая форма систематизации научного знания, которая выделяет из бесконечного многообразия реального мира именно те его сущностные связи, познание которых и составляет основную цель науки на том или ином этапе ее исторического развития. Этот процесс направляется философией, которая помогает осмыслить новые результаты науки через категориальную матрицу, обеспечивающую исследование принципиально новых (по сравнению с уже познанными) объектов [5].

B-четвертых, синтез знаний. Учитывая междисциплинарный характер глобальных проблем, с которым столкнулось человечество, и полидисциплинарный характер концепции устойчивого развития, есть основания вести речь об объединении научных знаний в систему. К середине ХХ в. дисциплинарно организованная наука (благодаря усилению интегративных связей между ее ветвями) сформировала три основных подсистемы общей научной картины мира - представления о неживой природе, сфере жизни и обществе. Но связь между этими подсистемами еще не была органичной, она обеспечивалась больше философскими идеями о развитии мира. В XXI в., в условиях активно идущих процессов глобализации, изменяющих все сферы нашего бытия, нарастающих глобальных проблем, касающихся всех стран и жизни каждого человека, четко проявилась тенденция междисциплинарного синтеза знаний и понимание контрпродуктивности ограничения обучения лишь специальными научными картинами мира, необходимости выстроить взаимодействие предметных онтологий разных дисциплин. Специальные научные картины мира, связанные с усилением дифференциации науки, формируют относительно автономные объекты исследуемой реальности. Постепенно начинает утрачиваться целостное видение мира. Однако простое соединение специальных картин мира не создаст новой единой картины [5]. Чтобы увидеть большее, пренебрегая меньшим, - напутствовал Н. Н. Моисеев [6], - чтобы дух человека не потерялся в мелочах. Как отмечал Огюст Конт [7], необходимо разработать философские принципы формирования общенаучной картины мира. В условиях обострения экологических проблем, понимание которых базируется, прежде всего, на междисциплинарном естественнонаучном знании, становится актуальным формирование целостной естественнонаучной картины мира в ее экологическом аспекте.

\section{Материалы и методы исследования}

Философская, научная и научно-педагогическая литература, документы ЮНЕСКО, «Основы государственной политики в области экологического развития России на период до 2030 года», документы ФГОС, Примерные основные образовательные программы - все эти материалы стали основой для изучения поставленной проблемы. Теоретические методы исследования: анализ, синтез, обобщение, аксиоматизация, абстрагирование.

\section{Результаты исследования и их обсуждение}

С середины прошлого столетия проблема интеграции знаний обрела новые смыслы в связи с появлением объединяющей все науки экологической проблематики, изучением разных сторон современного экологического кризиса, связанных с ним глобальных проблем и представлений об экологическом императиве. Экологический императив - ключевое понятие современной экологической культуры, образования для устойчивого развития, результат синтеза знаний разных учебных дисциплин, каждая из которых вносит свой вклад в формирование целостных представлений об объективных, допустимых природой, границах деятельности человека в окружающей социоприродной среде. Изучение физики, химии, биологии, физической географии дает возможность наполнить конкретным содержанием представления о системных запретах деятельности человека в окружающей среде, которые в условиях глобального мира действуют тотально, неотвратимо, проявляясь не только на глобальном, но и локальном и личностном уровнях. Содержание естественнонаучных дисциплин потенциально может предоставить доказательства того, что такие запреты носят не правовой и не этический, а объективный характер, с третейских позиций законов устойчивости экологических систем. Однако простое изучение глобальных проблем в разных естественнонаучных учебных предметах еще не позволяет раскрыть суть экологического императива. Просто рассказывая ребенку о многообразии жизненных форм, о том, как сложно устроен и красив наш мир, мы не продвинемся в обучении его экологии, не закрепим в его памяти так необходимые ему основы понимания мира, в котором ему предстоит жить [8].

Опираясь на онтологию и методологию естественнонаучного познания, общенаучные понятия и принципы науки, которые пронизывают ее фундамент, рассмотрим ключевые категории целостной естественнонаучной картины мира, позволяющие раскрыть сущность экологического императива как базовой идеи устойчивого развития. 
Понятие «природа» в естественнонаучной картине мира. Естественные науки - это науки о природе. Рассматривая проблему синтеза и систематизации естественнонаучных знаний, важно уточнить значение понятия «природа», которое употребляется в учебных текстах в трех значениях: 1) как весь материальный мир Вселенной, мироздание, универсум, законы которого едины для всех его форм: живой и неживой природы, человека, его сообществ и техносферы; 2) как совокупность косной и живой природы, что автоматически удаляет из предмета изучения общество и техносферу; 3) как места вне городов, загородные угодья (поля, леса, горы). В целях конкретизации объема понятия «природа» в широком смысле выделяют «первую природу»- естественное геологическое окружение и мир живых организмов; вторую - преобразованное, окультуренное геологическое окружение, сорта культурных растений и породы животных, измененные под влиянием культуры человека; третью природу - искусственную среду как показатель следующей ступени преобразования природного мира в результате научно-технической революции (мир техники, ксенобиотики, искусственный интеллект и т. д.).

Естественные науки изучают природу, понимаемую в широком смысле как материальный мир Вселенной, и в узком - как изучение гео- и биосферы. К сожалению, в учебных курсах как общего, так и профессионального образования зачастую не уточняется, какое именно значение вкладывается в понятие «природа».

В начальной школе учащиеся знакомятся с понятием «природа» в узком смысле - как все то, что не создано руками человека. В младших классах и в последующем обучении мир людей изучается отдельно, рассматриваются его особенности, отличия от живой и неживой природы, а связи с природой выстраиваются, с одной стороны, с точки зрения удовлетворения потребностей человека, а с другой стороны, в аспекте этических и правовых норм, которые устанавливаются самими людьми.

Целостная естественнонаучная картина мира, о которой мы ведем речь, оперирует понятием «природа» в широком смысле, что отражается в ее ключевых категориях: материальное единство мира, объективность и познаваемость, развитие, многообразие, система, самоорганизация, детерминизм.

Естественнонаучная картина мира о его материальном единстве. В основе онтологии естественнонаучной картины мира - доказательства материальности мира как основания его единства, которые предоставляются физикой, химией, биологией и физической географией. Представления о материальном единстве мира лежат и в основе концепции устойчивого развития как новой парадигмы отношения человека к окружающей его среде и эволюции жизни во Вселенной.

Материальное (не зависящее от какого-либо духа или сознания) единство мира - единое всеобщее материальное начало, лежащее в основе всего многообразия вещей и явлений мира, которое раскрывается через фундаментальные законы сохранения (вещества, энергии, импульса); единство физических явлений (механических, тепловых, электромагнитных и квантовых) и химических реакций (соединение, окисление, замещения, распад, окисление-восстановление) во Вселенной; универсальных видов материи (вещество, энергия, информация) при всем многообразии ее форм.

Следствием закона сохранения, например, вещества является закон о неустранимости отходов. «Образующиеся в процессе производственной деятельности отходы неустранимы бесследно, они могут быть лишь переведены из одной формы в другую или перемещены в пространстве, а их действие может быть растянуто во времени» [9]. Материя не исчезает, а лишь переходит из одной формы в другую, оказывая влияние на условия жизни. Барри Коммонер сформулировал это так: «все должно куда-то деваться» [10].

На Земле количество живого вещества биосферы для данного геологического периода есть константа: « ... Глобальная экосистема представляет собой единое целое, в рамках которого ничего не может быть выиграно или потеряно и которое не может являться объектом всеобщего улучшения; все, что было извлечено из нее человеческим трудом, должно быть возмещено. Платежа по этому векселю нельзя избежать; он может быть только отсрочен. Нынешний кризис окружающей среды говорит о том, что отсрочка очень затянулась» [10]. Как считал Н. Ф. Реймерс, к сожалению, подтверждается мысль о том, что «чем больше пустынь мы превратим в цветущие сады, тем более цветущих садов мы превратим в пустыни». «Ничто не дается даром», то есть любое новое приобретение в эволюции экосистемы обязательно сопровождается утратой какой-то части прежнего достояния и возникновением новых, все более сложных проблем. Не существует «бесплатных» для биосферы ресурсов - пространство, энергия, солнечный свет, вода, какими бы неисчерпаемыми они ни казались, неукоснительно оплачиваются любой расходующей их системой [9]. Поэтому современные экологи вывели еще один закон экологии - «на всех не хватит» (закон ограниченности ресурсов). Масса питательных веществ для всех форм жизни на Земле конечна и ограничена. Значительное увеличение численности и массы каких-либо организмов в глобальном масштабе может происходить только за счет уменьшения численности и массы других. В XXI в. действие этого закона приобретает острые формы политических, экономических и даже военных конфликтов в борьбе за природные ресурсы. Однако в живой природе и в человеческом обществе закон ограниченности ресурсов действует по-разному. Теория Мальтуса, превратившаяся сегодня в неомальтузианство - политически 
ангажированная под прикрытием экологических проблем идея передела жизненных ресурсов планеты является неофашизмом, объявляющим избранными людей богатых стран и оправдывающим насильственные методы борьбы с остальным населением (теория «золотого миллиарда» сегодня уже сократила число людей, достойных комфортной жизни на планете, сначала до одного миллиона, потом до 100 тыс.) [4].

Альтернативу идее передела природных ресурсов представляет концепция устойчивого развития, разрабатываемая под эгидой ЮНЕСКО со второй половины XX в. Это концепция формирования культуры сознательного и ответственного управления отношениями природы - общества - экономики при ведущей роли образования в этом процессе. В. И. Вернадский писал о знании, как геологической силе, способной обеспечить сохранение равновесия между антропогенным давлением на среду и восстановлением этой среды. Он обращал внимание на роль образования в преобразовании человеческих потребностей: осознанном отказе от необузданного потребительства и развитии потребностей духовного плана. В основе созданной им теории ноосферы - выполнение человеком своей биосферной функции в неизбежной трансформации биосферы под влиянием мысли и человеческого труда в ноосферу - геосферу, в которой разум становится доминирующим в развитии системы «человек - природа» [11], при этом именно образование призвано сыграть в этом решающую роль.

Идея развития в естественнонаучной картине мира. Принципами, которые позволили бы объединить различные видения природы, представленные в содержании разных естественнонаучных дисциплин, могли бы быть рационально осмысленные принципы развития и необратимости эволюции.

Систему взглядов В. И. Вернадского о биосфере называют учением об эволюции биосферы и ноосферы. Его, несомненно, следует рассматривать в качестве одной из существенных составляющих естественнонаучной картины мира. Биосфера, по мнению ученого, является результатом «достаточно длительной эволюции во взаимосвязи с неорганическими условиями· и может быть рассмотрена как закономерный этап развитии материи. Она предстает в качестве особого геологического тела, структура и функции которого определяются специфическими особенностями Земли и космоса» [11].

В своем учении универсального эволюционизма Н. Н. Моисеев связал между собой развитие Космоса (космогенеза), планеты Земля (геогенеза), живой оболочки на ней (биогенеза), появление человека и развитие общества (социогенеза) как закономерные этапы эволюции Универсума, мироздания. Согласно закону необратимости эволюции, или однонаправленности развития, мегасистемы эволюционируют только в одном направлении - от простого к сложному. Не случайно в 1972 г. Организацией Объединенных Наций была принята Конвенция о сохранении культурного и природного наследия, а образование для устойчивого развития во многих странах мира иначе называется образованием в области культурного и природного наследия каждого человека, которое мы получили от предков и должны передать потомкам, имеющим такие, как и мы, права на благополучную окружающую среду. Утрата как природного, так и культурного наследия безвозвратна, невосполнима и трагична для судьбы цивилизации. Закон необратимости эволюции гласит: организм (популяция, вид) не может вернуться к прежнему состоянию, осуществленному в ряду его предков. Все существующее сегодня на планете - от простых молекул до человека и его культуры - является результатом эволюции жизни в течение десятков и сотен миллионов лет, в ходе которых историческое развитие живых организмов приводило к усложнению их организации путем дифференциации органов и функций (закон усложнения организации). Населяющие сегодня планету виды растений и животных составляют всего лишь 1/1000 всех видов, которые прошли естественный отбор и смогли включиться в глобальный биотический круговорот. Биологические виды, которые не смогли вписаться, вымирали. Ход эволюции необратим. Утрата биологического разнообразия - основного фактора устойчивости природных экосистем необратима и не может быть компенсирована развитием современных технологий.

Изучение биологии доказывает существование цикличности изменений в биосфере, в частности, периодичности ее катастроф, которые носили природный, абиотический или биотический характер. Известно пять массовых вымираний биологических видов, например, вымирание до 80 \% биологических видов в пермский период, которые кардинально меняли условия жизни на планете, состав газов в атмосфере, круговороты веществ. В отличие от катастроф, экологические кризисы (когда среда обитания одного из видов или популяции изменяется так, что ставит под сомнение его дальнейшее существование, но при этом экологическая система способна к восстановлению) встречались в истории современной цивилизации. Они носили природный или антропогенный характер. Современный экологический кризис связан с антропогенной нехваткой редуцентов, накоплением ксенобиотиков; термодинамическим кризисом; деградацией земель; глобальными изменениями климата; загрязнением воздуха и мирового океана; истощение озонового слоя; нехваткой пресной воды; снижением биологического разнообразия; снижением адаптационных и защитно-компенсаторных механизмов человеческого организма; ростом в биосфере концентрации углекислого газа (в 2 раза за 800 лет и т. д.). Еще одна особенность современного экологического кризиса - опасность его превращения в глобальный, что приведет к экологической катастрофе, к потере окружающей средой качеств, к которым адаптировался человек в ходе своей эволюции. Проблема заклю- 
чается и с том, что современный экологический кризис происходит на фоне действия правила ускорения эволюции: с ростом сложности организации биосистем продолжительность существования вида в среднем сокращается, а темпы эволюции возрастают. Поэтому, сколько времени биосфера сможет выдерживать все возрастающую антропогенную - неизвестно. Цели устойчивого развития, принятые практически всеми странами мира к реализации, ставят задачу затормозить негативные процессы в биосфере, подготовить так называемую «экологическую революцию» - изменение типа хозяйствования на планете.

Естественнонаучная картина мира о системной организации материи. В основе современных научных представлений о единстве строения материи лежит идея о ее системной организации. Практически все объекты, которые современная наука включает в сферу своего исследования, носят системный характер. Среди совокупности общенаучных понятий особый статус в XX в. приобрели понятия, характеризующие различные типы системной организации объектов, общие принципы их взаимодействия, функционирования и развития. Естественнонаучные предметы изучают все типы систем: закрытые, замкнутые и открытые. Система - это совокупность элементов или отношений, закономерно связанных друг с другом в единое целое, которое обладает свойствами, отсутствующими у элементов или отношений их образующих. Система есть объект, целостность которого обеспечивается совокупностью связей и отношений между группами элементов, объединенных развернутыми в пространстве и во времени структурами [12]. Сложные системы (например, экологические) состоят из подсистем - вложенных и пересекающихся, содержащих общие элементы, относящихся к нескольким подсистемам сразу, которые выполняют в подсистемах функции, обеспечивающие реализацию целевой функции всей системы в целом. Вложенные и пересекающиеся системы невозможно разделить так, чтобы не нарушилась целостность хотя бы одной из них.

Системы классифицируются на замкнутые, которые, как и управление этой системой, не испытывают влияния внешней среды через обмен вещества и энергии; закрытые - обменивающиеся с окружающей средой энергией, но не веществом; системы открытые, связанные с окружающей средой обменом веществ и энергии. Открытые системы (природные, социоприродные, социальные) могут развиваться только за счет окружающей среды, использования ее материально-энергетических и информационных возможностей. Согласно закону оптимальности, наибольшую эффективность функционирования система достигает в некоторых характерных для нее пространственно-временных пределах (то есть, никакая система не может сужаться или расширяться до бесконечности). Размер системы должен соответствовать выполняемым ею функциям. Действует принцип минимального размера популяций: существует минимальный размер популяции, ниже которого ее численность не может опускаться [9].

В ходе изучения сложных открытых систем создаются основания к взаимодействию дисциплинарных онтологий физики, химии, наук о жизни, географии, космологии и появлению пограничных наук - биохимия, биофизика, медицинская география и др. Общие закономерности взаимосвязи «система - среда» обобщены в философски расширенной формулировке принципа дополнительности Нильса Бора. Жесткие системы (механические устройства и тоталитарно-автократические общественные структуры) лишены механизмов самоподдержания и потому обречены на постепенное разрушение, тем более скорое, чем агрессивнее для них окружающая среда.

Согласно Я. Пригожину, в открытых системах энтропия не возрастает, а уменьшается до тех пор, пока не достигается минимальная постоянная величина, всегда больше нуля (принцип сохранения упорядоченности). Таким образом, деятельность живых систем (организмов, их сообществ) неэтропийна, совершается работа по увеличению степени их структурированности. Для живых систем, согласно Л. Онсагеру, при вероятности развития процесса в некотором множестве направлений, допускаемых началами термодинамики, реализуется то, которое обеспечивает минимум рассеивания энергии (принцип экономии энергии). При этом оптимальная эффективность всегда меньше максимальной, то есть высокая продуктивность дает низкую надежность (устойчивость). Это важно понимать при создании агроценозов. Отсюда и закон максимизации энергии и информации: наилучшими шансами на самосохранение обладает система, в наибольшей степени способствующая поступлению, выработке и эффективному использованию энергии и информации; максимальное поступление вещества не гарантирует системе успеха в конкурентной борьбе [9]. Н. Н. Моисеев обозначает его как принцип экономии энтропии, дающей «преимущество» сложным системам перед простыми. Этот принцип звучит так: если в данных условиях возможны несколько типов организации материи, не противоречащих законам сохранения и другим принципам, то реализуется и сохранит наибольшие шансы на стабильность и последующее развитие именно тот, который позволяет утилизировать внешнюю энергию в наибольших масштабах, наиболее эффективно [13]. Все эти характеристики крайне важны для организации рационального природопользования и прогноза изменений экологических систем и биосферы, в целом, при изменении показателей их внутренней и внешней среды.

Проблема самоорганизации систем в естественнонаучной картине мире. Довольно длительное время самоорганизация соотносилась только с живыми системами, что же касается объектов неживой 
природы, считалось: если они и эволюционируют, то лишь в сторону хаоса и беспорядка, соответствующим вторым началам термодинамики. Сегодня представления об открытых самоорганизующихся системах находят подкрепление в самых различных областях знания, стимулируя в них разработку эволюционных идей [5].

Способность биосферы как сложной саморегулируемой и самоорганизующейся экологической мегасистемы непрерывно поддерживать на планете определенный круговорот веществ, сохранять в основных чертах свою структуру, характер связей и функций элементов, то есть поддерживать гомеостаз, является условием сохранения качества окружающей природной среды, необходимого для жизни человека. Гомеостаз - свойство высокоорганизованных самоорганизующихся систем поддерживать основные функции, параметры и тренды развития. Природные экологические системы способны к саморегуляции и самовосстановлению при условии незначительного изменения среды их обитания. Пока изменения среды слабы и произведены на небольшой площади, они ограничиваются конкретным локальным пространством или «гасятся» в цепи иерархии экосистем на уровне естественных круговоротов вещества и энергии на Земле. Саморегуляция экологической системы - ее способность сохранять постоянными биологическое разнообразие (состав биоты), биологическую продукцию и круговороты элементов питания [9].

Жизнь на Земле имеет экосистемную форму организации, поэтому исключительную важность для ее понимания играет учение универсального эволюционизма Н. Н. Моисеева, в котором в единое целое объединяются идеи теории самоорганизующихся систем разной степени сложности и эволюционного подхода. Доказано, что в открытых системах, находящихся в неравновесном состоянии, возникают и формируются новые структуры за счет внутренних кооперативных процессов, под влиянием различного рода флуктуаций, благодаря чему осуществляется переход от одного типа самоорганизующейся системы к другой, а эволюция систем в конечном счете приобретает направленный характер. Саморазвивающиеся объекты характеризуются иерархией уровней и появлением по мере развития все новых уровней, которые воздействуют на ранее сложившиеся и видоизменяют их. Примером самоорганизующейся мегасистемы является биосфера, способная адаптироваться к широкому спектру условий [13]. Исключение составляют астрофизические катаклизмы, способные создать на планете, режим, несовместимый с любой формой земной жизни, например, температурный. К сожалению, в учебных текстах до настоящего времени можно встретить неадекватные представления о возможностях экосистем к самоорганизации: «Природа - это некий хрупкий, легко разрушающийся организм, и человек способен нанести ей непоправимый вред: одним неловким движением разбить, разрушить, как хрустальную вазу» [14]. Нередко употребляется словосочетание «природа погибнет». На самом деле, силы природы, доказывает В. И. Вернадский, настолько огромны, что деятельность человек несопоставима с ними. Часто неверно истолковывают его фразу о том, что «Человек становится геологической силой, способной изменить лик Земли», вкладывая в нее не тот смысл, который делал этот великий ученый и мыслитель. Он отмечал: «Основной геологической силой, создающей ноосферу, является рост научного знания» [11]. В условиях ноосферы человек сможет стать геологической силой. Он познает с помощью науки силы природы и направит их на сохранение устойчивости биосферы. Именно наука, знания могут сделать так, что воздействие на природу будет природосообразным, человечество станет частью биосферы, включится в ее естественный большой геологический круговорот без его нарушения. В противном случае изменение качества окружающей человека природной среды, ее физико-химического состава в условиях стремительного роста техносферы может стать несовместимым с условиями жизни людей, и природа продолжит эволюционировать без них.

Естественнонаучная картина мира о многообразии и разнообразии природы. Знания, получаемые из физики, химии, биологии, свидетельствуют о многообразии свойств окружающей среды (цвета, звуков, движений; форм, химического состава и т. д.), а также всевозможных приспособлений к ним живых существ и их сообществ. Формируются знания о природном разнообразии: ландшафтном, биологическом, генетическом. Они важны для понимания системного закона необходимого разнообразия Эшби. Согласно этому закону, система, чтобы отвечать задачам управления и быть эффективной, должна обладать возможностью изменять свое состояние в ответ на предполагаемое возмущение. Многообразие возмущений требует соответствующего ему многообразия возможных состояний живых систем и их разнообразия в сообществах. Отсутствие или недостаточность многообразия, ответных реакций или природного разнообразия (ландшафтного, биологического или генетического) может свидетельствовать о нарушении целостности подсистем, составляющих данную систему. Закон необходимого разнообразия объясняется, в частности, неравномерностью развития частей системы: системы одного уровня иерархии развиваются не строго синхронно, в то время как одни достигают более высокой стадии развития, другие остаются в менее развитом состоянии.

Одна из наиболее острых проблем современного экологического кризиса в XXI в. - нарастающий дефицит не столько полезных ископаемых на Земле, сколько способности живых организмов, в том числе 
человека, их сообществ приспосабливаться к очень быстро изменяющейся окружающей среде, что способствует сокращение естественного многообразия окружающего мира и появление новых факторов, ранее не свойственных биосфере. Это приводит к превышению пределов, границ выносливости ряда биологических видов и устойчивости экологических систем, угрожает снижением биоразнообразия на планете, создает риски для залкнутости круговорота в глобальном масштабе. Такие риски возрастают в условиях ускорения эволючии с ростом сложности организации систем, проявляющейся в органическом мире, человеческой истории, в развитии техники.

Изучение физики, химии, систематики растений и животных дает богатый материал для понимания значения многообразия окружающего мира и природного разнообразия для сохранения экологической ниши человеческого вида и устойчивого развития общества. Уникальную ценность для всего мира имеет природное богатство России. Благодаря сохранению территорий естественных экологических систем, дикая природа Россия обеспечивает 10 \% устойчивости биосферы. По запасам пресной воды, количеству биоразнообразия, территорий болот и лесов Россия является самым крупным экологическим донором на планете. Действия стран мира по пути сохранения природного разнообразия на планете нашли отражение в Целях устойчивого развития до 2030 г.

Детерминизм в естественнонаучной картине мира. Детерминизм - общенаучное понятие и философское учение о причинности, закономерности, генетической связи, взаимодействии и обусловленности всех явлений и процессов, происходящих в мире, результат обобщения конкретно-исторических и конкретно-научных концепций. Исходной предпосылкой принципа детерминизма является существование всеобщей универсальной взаимосвязи всех явлений.

Биологические процессы не противоречат законам химии и физики, а химические процессы не перечеркивают законы физики. Свойства химических элементов, определяемые их положением в таблице Менделеева, предполагают особенности их физических и химических свойств, а также роль в физиологии органов и тканей живых организмов, в биогенной миграции атомов в биосфере.

Становление целостной естественнонаучной картины мира создает предпосылки формирования картины социального развития, которое детерминируется экологическими условиями поддержания жизни человека. По мнению известного специалиста в области метагеографии Д. Н. Замятина, «...отсутствие разработанных механизмов взаимодействия с традиционными естественными науками, расслоение, прежде всего, достаточно единого массива гуманитарных знаний на большое количество обособленных и слабо связанных когнитивных областей... является одним из «самых мощных» препятствий (и) для гуманитарных наук [15].

Абсолютизации социологических схем развития общества, которые игнорируют, а то и исключают в судьбах народов и культур природно-географические и демографические факторы, упрощенно толкуют экономическое учение Маркса о классовой борьбе и сменах экономических формаций, противостоит географический детерминизм, раскритикованный в свое время, что затормозило развитие теории детерминаций развития общества [16].

Совокупность формируемых на естественнонаучных дисциплинах представлений о единстве материального мира, его познаваемости, объективности научного знания, развитии мира и необратимости эволюции, единстве строения материи, системности, самоорганизации, многообразии, детерминации являются ключевыми для раскрытия сущности понятия экологического императива - базового в концепции устойчивого развития.

Роль естественнонаучной картины мира в формировании представлений об экологическом императиве - базовом понятии устойчивого развития. Понятие экологического императива было введено Н. Н. Моисеевым в 80-х гг. XX в. как границы допустимой активности человека, которую он не имеет права переступать ни при каких обстоятельствах. Ученый отмечал: «Экологический императив - это некоторое множество свойств окружающей среды, зависящих от особенностей цивилизации, изменение которых человеческой деятельностью недопустимо ни при каких обстоятельствах» [13]. Проводя границу с экологическим императивом Канта, Н. Н. Моисеев подчеркивал объективный характер ограничения деятельности человека в окружающей среде со стороны природы. Экологический императив не зависит от воли человека, но следование ему - вопрос знаний, умений и ценностей человека. Людям необходимо знать пределы вмешательства в природу, допустимые уровни нагрузки на биосферу, уровни мутагенеза и др., то есть границы своей деятельности в общепланетарном масштабе.

Экологический императив исходит из существования границ колебания незаменимых для жизни факторов окружающей среды, которые определяются лимитом выносливости организма или пределами устойчивости экологических систем. За этими границами в живых системах наступают необратимые процессы, приводящие к их гибели или деградации, что накладывает объективные ограничения на деятельность человека в окружающей среде, ставит проблему меры ее преобразования. Действие экологического императива относится к сложным открытым системам, поведение которых сложно наблюдать в жизни в силу 
больших пространственно-временных масштабов происходящих в них изменений. Для лучшей наглядности могут быть полезными аналогии детерминации на уровне физических, химических и биологических процессов.

Так, из физики известно, что устойчивость системы любой природы, сохранение ее характеристик имеет пределы. В физике первый закон Ньютона постулирует наличие такого явления, как инерция тел - явление сохранения телом скорости движения (по величине и направлению), когда на тело не действуют никакие другие силы. Инертность - свойство тел сопротивляться изменению их текущего состояния. Второй закон Ньютона определяет как взаимодействие системы со средой (инертность) зависит от внутренних свойств системы (массы тела). Третий закон устанавливает, что силы всегда возникают парами (действие и противодействие), хотя они могут не уравновешиваться. Для описания результатов их действия и противодействия используются такие характеристики, как хрупкость и пластичность. Как метафоры они используются и для описания состояния экологических систем под влиянием внешних воздействий.

Наглядный образ экологического императива может быть представлен с помощью физического опыта «бочка Либиха»: вода, налитая в бочку, в стенках которой на разном уровне сделаны отверстия, выливается, достигая самого нижнего отверстия, высота его расположения является лимитирующей, ограничивающей возможность наполнения бочки водой. Очевидно, что это ограничение носит объективный характер.

Параллель с действием экологического императива можно провести и с помощью химии, использовав принцип Ле-Шатье-Брауна. Согласно ему, если на систему, находящуюся в состоянии химического равновесия, оказано внешнее воздействие (температура, давление, концентрация, внешнее электромагнитное поле), то равновесие сместится в направлении той реакции, которая ослабляет это воздействие. Ле-Шателье сформулировал эту закономерность как термодинамический принцип подвижного равновесия, который применим к равновесию любой природы: механическому, тепловому, химическому, электрическому.

Несмотря на сходство, закономерности, имеющие место для разных форм движения материи, не тождественны. Прямой перенос, прямые аналогии закономерностей физической, химической, биологической и социальной форм движения материи недопустимы: каждая из них имеет свою специфику [9].

В биологии, имеющей дело с открытыми самоорганизующимися системами, действует закон внутреннего динамического равновесия Н. Ф. Реймерса. Согласно этому закону, вещества, энергия, информация и динамические качества отдельных природных (экологических) систем и их иерархии взаимосвязаны настолько, что любое изменение одного из этих показателей вызывает сопутствующие функциональноструктурные количественные перемены, сохраняющие общую сумму вещественно-энергетических, информационных и динамических качеств экосистем, где эти изменения происходят, или в их иерархии [9].

Следствием закона являются:

- закон оптимальности - любая система функционирует с наибольшей эффективностью в некоторых характерных для нее пределах колебания параметров окружающей среды;

- закон минимума Либиха - успешную жизнедеятельность организма ограничивает экологический фактор, количество и качество которого близок к минимуму, необходимому организму;

- представление о базовых незаменимых факторах окружающей среды, которые невозможно заменить другими.

Факторы, сдерживающие развитие организмов и их сообществ из-за недостатка или их избытка по сравнению с потребностями, называются лимитирующими. Закон внутреннего динамического равновесия и его следствия являются фундаментальной основой для организации природопользования и разработки природоохранной политики в народном хозяйстве. Они дают возможность ставить в экологии вопрос о выносливости биологических видов и устойчивости природных экосистем, включая самую большую природную экосистему - биосферу. Пределами выносливости называют минимальное и максимальное значения факторов (физического, химического, информационного), при которых возможна жизнедеятельность. Границы, за пределами которых наступает гибель организмов, являются нижними и верхними границами выносливости вида. Их называют критическими точками. Расчеты ученых позволяют приблизительно определить порог устойчивости (допустимого возмущения) биосферы: биота сохраняет способность контролировать условия окружающей среды, если человек в ходе своей деятельности использует не более 1 \% ее чистой первичной продукции. Остальная часть продукции должна перераспределиться между видами, выполняющими функции стабилизации окружающей среды. Отсюда правило одного процента: изменение энергетики природной среды в среднем на $1 \%$ выводит последнюю из состояния равновесия. Все крупные природные явления на Земле (извержения вулканов, мощные циклоны и т. п.), как правило, имеют суммарную энергию, не превышающую 1 \% энергии солнечного излучения, падающего на ее поверхность. Однако в XXI в., согласно расчетам, порог допустимого воздействия на биосферу уже превышен, и для предотвращения глобальных изменений в составе окружающей среды (прежде всего, в количестве углекислого газа в атмосфере) необходимо сократить площадь нарушенных земель с 61 до 38 \%. 


\section{Заключение}

Поиск интегральной парадигмы, объясняющей и прогнозирующей взаимоотношения общества и природы в XXI в., может опираться лишь на синтез гуманитарного знания с естественнонаучным в самом широком его диапазоне: на представления о природе как материальном мире Вселенной, Универсуме, законам которого подчиняется все сущее; об общей судьбе человека с биосферой; о том, что обществу необходимо научиться управлять собой и организовывать свою жизнедеятельность в пределах, детерминируемых экологическим императивом.

Как предотвратить катастрофическое изменение биосферного уровня организации жизни, необратимое нарушение глобального биогеохимического круговорота веществ, когда биосфера достигает точки невозврата в прежнее состояние, какой должна стать во всех сферах жизни общества революция экологического управления? Ответы на многие эти вопросы могут находиться в естественнонаучной картине мира, осмысленной на основе ценностей био- и экологической этики; природного и культурного разнообразия, мира и ненасилия, устойчивого развития [16;17].

Академик Н. Н. Моисеев отмечал: «Человечество подошло к порогу, за которым нужны и новая нравственность, и новые знания, новый менталитет, новая система ценностей. Необходимо избрать иную, духовно-экологическую, стратегию развития; в противном случае человечество может быть сметено с Земли в результате глобальных кризисов» [6].

\section{Библиографические ссылки}

1. Резолюция A/RES/70/1 Генеральной Ассамблеи ООН от 25 сентября 2015 года «Повестка дня в области устойчивого развития на период до 2030 года» [Интернет]. [Процитировано 2 декабря 2020 г.]. Доступно по: https://unctad.org/system/files/ official-document/ares 70d1 ru.pdf.

2. Guterres A. Remarks to the General Assembly on the Secre-tary General's priorities for 2020. [Internet]. [Cited 2020 April 18]. Available from: https://www.un.org/sg/en/content/sg/speechts/2020-01-22/remarks-general-assembly-priorities-for-2020.

3. Берлинская декларация об образовании в интересах устойчивого развития, принятая на Всемирной конференции ЮНЕСКО по образованию для устойчивого развития [Интернет]. 2021. Доступно по: https://en.unesco.org/sites/default/files/esdfor2030berlin-declaration-ru.pdf

4. Von Weizsaecker T, Wijkman A. Come On! Capitalism, Short-termism, Popu-lation and the Destruction of the Planet. New York: Springer; 2018.

5. Степин ВС, Кузнецова ЛФ. Научная картина мира в культуре техногенной цивилизации. Москва: ИФ РАН; 1994.274 с.

6. Моисеев НН. Универсум. Информачия. Общество. Москва: Устойчивый мир; 2001. 200 с.

7. Конт О. Курс положительной философии. Философия и общество. 1999;1:12-24.

8. Ердаков ЛН. Экология. Томск [б. н.]; 2007. 170 с.

9. Реймерс НФ. Экология. Москва: Журнал Россия Молодая; 1994. 367 с.

10. Коммонер Б. Замылкающийся круг. Москва: Гидрометеиздат; 1974. 280 с.

11. Вернадский ВИ. Биосфера и ноосфера. Москва: Айрис-Пресс; 2013. 573 с.

12. Блауберг ИВ, Садовский ВН, Юдин ЭГ. Системный подход: предпосылки, проблемы, трудности. Москва: Знание; 1969.48 с.

13. Моисеев НН. Современный антропогенез и циивилизаиионные разломы. Экологополитологический анализ. Москва: [б. н.]; 1994. c. 46

14. Дзятковская ЕН, Трубицына ЛВ, редакторы. Образование для устойчивого развития во внеурочной деятельности. Москва: Издательство Академии им. Н. Е. Жуковского; 2014. 88 с.

15. Замятин ДН. Метагеография: Пространство образов и образы пространства. Москва: Аграф; 2004. 512 с.

16. Мягков ГП, Недашковская НИ. От географического детерминизма к экологической истории: гуманитарии в преддверии нового «поворота». В: Проблемы просвещения, истории и культуры сквозь призму этнического многообразия России. Чебоксары: Издательство «Среда»; 2018. с. 436-444.

17. Global Challenges Foundation. Global Catastrophic Risks and International Collaboration. Opinion poll 2020. Report [Internet]. [Cited 2020 November 18]. Available from: C:/user/Desktop/GCF_Global_Challenges.2020-High.pdf.

18. Биоэтика и биотехнологии: предель улучшения человека. Москва: Издательство Московского гуманитарного университета; 2017. 240 c.

\section{References}

1. UN General Assembly Resolution A/RES/70/1 of September 25, 2015, The 2030 Agenda for Sustainable Development. [Internet]. [Cited 2020 December 2]. Available from: https://unctad.org/system/files/official-document/ares 70d1_en.pdf.

2. Guterres A. Remarks to the General Assembly on the Secre-tary General's priorities for 2020 [Internet]. [Cited 2020 April 18]. Available from: https://www.un.org/sg/en/content/sg/speechts/2020-01-22/remarks-general-assembly-priorities-for-2020.

3. Berlin Declaration on Education for Sustainable Development, adopted at the UNESCO World Conference on Education for Sustainable Development [Internet]. May 2021. Available from: https://en.unesco.org/sites/default/files/esdfor2030-berlindeclaration-ru.pdf.

4. Von Weizsaecker T, Wijkman A. Come On! Capitalism, Short-termism, Popu-lation and the Destruction of the Planet. New York: Springer; 2018

5. Stepin VS, Kuznetsova LF. Nauchnaja kartina mira v kulture tehnogennoy tsivilizatsii [The scientific picture of the world in the culture of a technogenic civilization]. Moscow: IF RAN; 1994. 274 p. Russian. 
6. Moiseev NN. Universum. Informatsija. Obshchestvo [Universe. Information. Society]. Moscow: Sustainable World; 2001.200 p. Russian.

7. Cont OA. Kurs polozhitelnoy philosophii [Course in Positive Philosophy]. Philosophy and Society. 1999;1:12-24. Russian.

8. Erdakov LN. Ecologiya [Ecology]. Tomsk: [publisher unknown]; 2007. 170 p. Russian.

9. Reimers NF. Ecologiya [Ecology]. Moscow: Zhurnal Rossiya Molodaya; 1994. 367 p. Russian.

10. Kommoner B. Zamykayushchijsa krug [Closing Circle]. Moscow: Hydrometeorological Institute; 1974. 280 p. Russian.

11. Vernadsky VI. Biosphera i noosphera [Biosphere and Noosphere]. Moscow: Iris-Press; 2013. 573 p. Russian.

12. Blauberg IV, Sadovsky VN, Yudin EG. Sistemnyj podhod: predposylki. Problem, trudnosti [Systemic approach: prerequisites, problems, difficulties]. Moscow: Znanie; 1969. 48 p. Russian.

13. Moiseev NN. Sovremennyj antropogenez I tsivilizatsionnye razlomy. Ekologopolitologicheskiy analiz [Modern Anthropogenesis and Civilization Fractures. Ecological and Political Analysis]. Moscow: [publisher unknown]; 1994. p. 46. Russian.

14. Dzyatkovskaya EN, Trubitsyna LV, editors. Obrazovaniye dla ustoychivogo razvitiya vo vneurochnoy deyatelnosti [Education for Sustainable Development in extracurricular activities]. Moscow: Publishing house of the Academy named after NE. Zhukovsky; 2014. 88 p. Russian.

15. Zamyatin DN. Metageographiya: Prostranstvo obrazov i obrazy prostranstva [Metageography: Image Space and Image Space]. Moscow: Agraf; 2004. 512 p. Russian.

16. Myagkov GP, Nedashkovskaya NI. Ot geograficheskogo determinizma k ecologicheskoy istorii: gumanitarii v preddverii novogo "povorota» [From geographical determinism to ecological history: humanities on the threshold of a new "turn"]. In: Problems of Education, History and Culture through the prism of ethnic diversity in Russia. Cheboksary: Publishing house «Sreda»; 2018. p. 436-444. Russian.

17. Global Challenges Foundation. Global Catastrophic Risks and International Collaboration. Opinion poll 2020. Report [Internet]. [Cited 2020 November 18]. Available from: C:/user/Desktop/GCF_Global_Challenges.2020-High.pdf.

18. Bioetika i biotehnologii: predely uluchsheniya cheloveka [Bioethics and biotechnology: the limits of human improvement]. Moscow: Publishing house of the Moscow Humanitarian University; 2017. 240 p. Russian. 